\title{
Visible Light Activated Room Temperature Gas Sensors Based on $\mathrm{CaFe}_{2} \mathrm{O}_{4}$ Nanopowders ${ }^{+}$
}

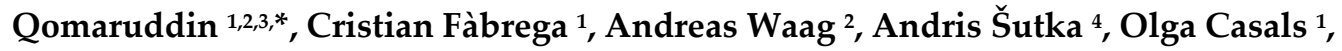 \\ Hutomo Suryo Wasisto ${ }^{2}$ and Joan Daniel Prades ${ }^{1}$ \\ 1 MIND-IN2UB, Department of Electronic and Biomedical Engineering, Universitat de Barcelona, \\ E-08028 Barcelona, Spain; cfabrega@el.ub.edu (C.F.); ocasals@el.ub.edu (O.C.); dprades@el.ub.edu (J.D.P.) \\ 2 Institute of Semiconductor Technology (IHT) and Laboratory for Emerging Nanometrology (LENA), \\ Technische Universität Braunschweig, 38106 Braunschweig, Germany; \\ a.waag@tu-braunschweig.de (A.W.); h.wasisto@tu-braunschweig.de (H.S.W.) \\ 3 Research Center for Physics, Indonesian Institute of Sciences (LIPI), Tangerang Selatan 15314, Indonesia \\ 4 Research Laboratory of Functional Materials Technologies, Faculty of Materials Science and Applied \\ Chemistry, Riga Technical University, 1048 Riga, Latvia; andris.sutka@rtu.lv \\ * Correspondence: qomaruddin@el.ub.edu; Tel.: +34-934-034-804 \\ † Presented at the Eurosensors 2018 Conference, Graz, Austria, 9-12 September 2018. \\ Published: 4 December 2018
}

\begin{abstract}
Gas sensors based on $\mathrm{CaFe}_{2} \mathrm{O}_{4}$ nanopowders, which are $p$-type metal oxide semiconductor (MOX), have been fabricated and assessed for ethanol gas monitoring under visible light activation at room temperature. Regardless of their inferior sensitivity compared to thermally activated counterparts, the developed sensors have shown responsive sensing behavior towards ethanol vapors confirming the ability of using visible light for sensor activation. LEDs with different wavelengths (i.e., $465-590 \mathrm{~nm}$ ) were employed. The highest sensitivity $(3.7 \%)$ was reached using green LED activation that corresponds to the band gap of $\mathrm{CaFe}_{2} \mathrm{O}_{4}$.
\end{abstract}

Keywords: $\mathrm{CaFe}_{2} \mathrm{O}_{4}$ nanopowders; gas sensors; $p$-type metal oxide semiconductor; visible light activated room temperature

\section{Introduction}

There are plenty of gas sensor types that have been developed with different materials and working principles. The conductometric gas sensors attract much attention due to several advantages such as simplicity in measurement setup and the ease of miniaturization for portable instruments. Typically, most conductometric gas sensors based on metal oxides ( $n$ - and $p$-type) need heat to reach the working temperature [1,2]. However, the heat-driven gas sensors have several disadvantages, such as high power consumption, extreme operation conditions and technical limitations in the detection of flammable or explosive analytes because of safety issues.

Many attempts have been made to decrease the operating temperature and to improve the sensitivity and stability of MOX gas sensors (e.g., noble metal doping [3], transition metal oxide incorporation [4], self-heated [5,6], and light irradiation [7,8]). Among these, irradiating light on the surface of metal oxides (e.g., $\mathrm{ZnO}[4]$ and $\mathrm{TiO}_{2}[9]$ ) is the most studied and promising method to achieve room temperature sensitivity. Light-activated sensors offer some advantages, such as the possibility to drastically reduce the power consumption by scaling down the light sources (LED platforms) or the possibility to use other technologies incompatible with heat driven sensors (i.e., functionalization). Also, most of the available conductometric sensing devices are based on wide band gap materials (e.g., $\mathrm{ZnO}$ and $\mathrm{SnO}_{2}$ ), which is need UV light to activate the absorption and desorption processes occurring on the surface of the sensing material. The efficiency of UV LEDs is 
however far from being competitive compared to visible LEDs. Therefore, materials with lower band gaps will be desirable for low power consumption gas sensor devices. In this work, we evaluated $\mathrm{CaFe}_{2} \mathrm{O}_{4}$ nanopowders for ethanol sensing under visible light exposure employing LEDs at room temperature. Since $\mathrm{CaFe}_{2} \mathrm{O}_{4}$ stands out as a potential candidate [1] because of its suitable band gap $[1.9 \mathrm{eV}]$ for visible light-driven sensors.

\section{Experimental Details}

Sol-gel auto-combustion method was used to synthesize $\mathrm{CaFe}_{2} \mathrm{O}_{4}$ nanopowders [1]. Goldinterdigitated electrodes (Au-IDE) on glass was (MicruX Technology, Asturias, Spain) used as electronic platform for measuring the electrical characteristics of the $\mathrm{CaFe}_{2} \mathrm{O}_{4}$. The IDE size is $(10 \mathrm{~mm}$ $\times 6 \mathrm{~mm} \times 0.75 \mathrm{~mm}$ ), with 90 pairs of electrodes having a separate distance of $10 \mu \mathrm{m}$ and a width of 10 $\mu \mathrm{m} . \mathrm{CaFe}_{2} \mathrm{O}_{4}$ nanopowders were deposited on the surface of the IDEs by drop casting process. $20 \mu \mathrm{L}$ of $\mathrm{CaFe}_{2} \mathrm{O}_{4}$ was dropped on the IDE while keeping the temperature between $40-90^{\circ} \mathrm{C}$. Afterwards, an annealing process at $450^{\circ} \mathrm{C}$ for $1 \mathrm{~h}$ with a ramping level of $5 \mathrm{C} / \mathrm{min}$ was applied in order to fix the material onto the substrate and obtain a good electrical contact with the Au-IDEs.

Gas sensing experiments were conducted in a customized chamber of $20 \mathrm{~mL}$ in volume. The gas flow was maintained stable at $200 \mathrm{~mL} / \mathrm{min}$ during all the measurements. Reference gaseous atmospheres were provided by independent mass flow controllers blending synthetic air (SA) and ethanol (100 ppm in SA). To investigate $\mathrm{CaFe}_{2} \mathrm{O}_{4}$ optoelectronic properties, resistance measurements were conducted under synthetic air flow with different LED wavelengths (i.e., blue ( $465 \mathrm{~nm}$ ), green $(520 \mathrm{~nm})$, and yellow $(590 \mathrm{~nm})$ ). In order to determine the sensitivity of the $\mathrm{CaFe}_{2} \mathrm{O}_{4}$ sensors towards reducing gases, different concentrations of ethanol vapors (i.e., from 50 to $100 \mathrm{ppm}$ with an interval of $10 \mathrm{ppm}$ ) were then applied to the chamber under LED illumination. The response was defined as $\left[\left(R_{g}-R_{a}\right) / R_{a}\right] \times 100 \%$, where $R_{g}$ and $R_{a}$ are the electrical resistances of the sensor when it is exposed to ethanol and in the air, respectively. The response time and recovery time was defined as the time spent by a sensor to achieve $90 \%$ of the total resistance change during the adsorption and desorption process, respectively. All experiments were performed at room temperature.

\section{Results and Discussion}

The as-prepared sample powders are composed of amorphous-like anisotropically shaped and closely packed grains. Figure 1a shows an SEM image of the surface sensor on the Au-IDE after the annealing process. The porous structures of interconnected grains were observed, while the grains keep their anisotropic shape. The size of individual grains of smaller dimensions varies from 70 to $300 \mathrm{~nm}$, while the length of anisotropic nanoparticles is up to $650 \mathrm{~nm}$. Particles are very well interconnected and fused together, in which at the same time they maintain open structures for gas diffusion. Gas-accessible microstructures are preferred for a high gas response [1]. From the UV-vis diffuse reflectance spectra (DRS) of the sample indicate efficient visible light adsorption and the band gap energy of $\mathrm{CaFe}_{2} \mathrm{O}_{4}$ is $\sim 1.9 \mathrm{eV}$ [10], which was corroborated from the optoelectronic response to different LED wavelengths (Figure 1b). Band to band absorption was observed up to $590 \mathrm{~nm}(2.1 \mathrm{eV})$ wavelengths.
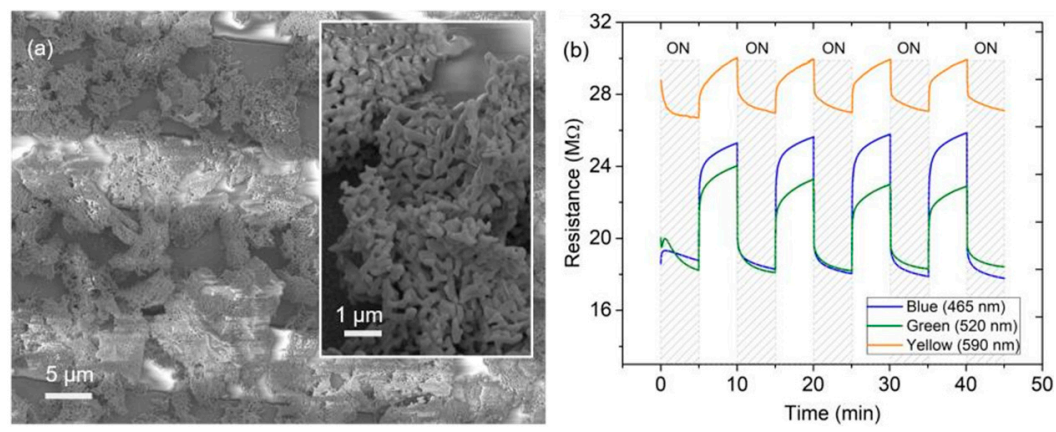

Figure 1. (a) SEM images of a gas sensor based on $\mathrm{CaFe}_{2} \mathrm{O}_{4}$ nanopowders and (b) their behaviors under exposures of visible light from LEDs with different wavelengths. 
To investigate the sensitivity of the $\mathrm{CaFe}_{2} \mathrm{O}_{4}$ sensors towards reducing gases, different concentrations of ethanol vapors (i.e., from 50 to $100 \mathrm{ppm}$ with an interval of $10 \mathrm{ppm}$ ) were then applied to the chamber under LED illumination. The first phenomenon to note was that the resistance increased in presence of ethanol (reducing gas), confirming that $\mathrm{CaFe}_{2} \mathrm{O}_{4}$ is a $p$-type material. When $\mathrm{CaFe}_{2} \mathrm{O}_{4}$ is exposed to air, oxygen molecules are adsorbed on the surface and the electrons are extracted from the conduction band (CB). The kinetic reaction can be explained in the following equations [2]:

$$
\begin{aligned}
& \mathrm{O}_{2} \text { (gas) } \leftrightarrow \mathrm{O}_{2} \text { (ads) } \\
& \mathrm{O}_{2(\mathrm{ads})}+\mathrm{e}^{-} \leftrightarrow \mathrm{O}_{2^{-}(\mathrm{ads})} \\
& \mathrm{O}_{2}{ }^{-}(\mathrm{ads})+\mathrm{e}^{-} \leftrightarrow 2 \mathrm{O}_{2}{ }^{-}{ }^{(\mathrm{ads})} \\
& \mathrm{O}^{-}{ }_{(\mathrm{ads})}+\mathrm{e}^{-} \leftrightarrow \mathrm{O}_{2}{ }^{-}{ }^{(\mathrm{ads})}
\end{aligned}
$$

When the sensor is exposed the ethanol vapors, the ethanol molecules are absorbed on the surface of the sensors and react with absorbed oxygen species to form water vapor $\left(\mathrm{H}_{2} \mathrm{O}\right)$ and $\mathrm{CO}_{2}$.

$$
\begin{aligned}
& \mathrm{C}_{2} \mathrm{H}_{5} \mathrm{OH}(\text { ads })+\mathrm{O}_{(\mathrm{ads})} \leftrightarrow \mathrm{CH}_{3} \mathrm{COH}_{(\mathrm{ads})}+\mathrm{H}_{2} \mathrm{O}+\mathrm{e}^{-} \\
& \mathrm{CH}_{3} \mathrm{COH}_{(\text {ads })}+6 \mathrm{O}^{-} \text {(ads) } \leftrightarrow 2 \mathrm{CO}_{2}+3 \mathrm{H}_{2} \mathrm{O}+12 \mathrm{e}^{-}
\end{aligned}
$$

On exposure to ethanol, the gas molecules will react with pre-absorbed oxygen. The reaction release free electrons, which naturalize the hole in the $p$-type of oxide semiconductor, thereby increasing the measured resistance.

Figure $2 \mathrm{a}-\mathrm{c}$ show the dynamic response to different concentrations of ethanol under illumination of blue, green, and yellow LEDs. The maximum sensitivity of $\mathrm{CaFe}_{2} \mathrm{O}_{4}$ is $3.7 \%$ at 100 ppm for green LED (Figure 2d). This maximum response corresponds to the maximum absorption of $\mathrm{CaFe}_{2} \mathrm{O}_{4}(520 \mathrm{~nm})$. In this case, the response and recovery times were $\sim 22 \mathrm{~min}$ and $\sim 49 \mathrm{~min}$, respectively. Overall, the obtained results provide evidence that $\mathrm{CaFe}_{2} \mathrm{O}_{4}$ is a good candidate for visible light driven gas sensor because of its suitable band gap (i.e., energy of visible light spectra is $1.9-2.7 \mathrm{eV})$.

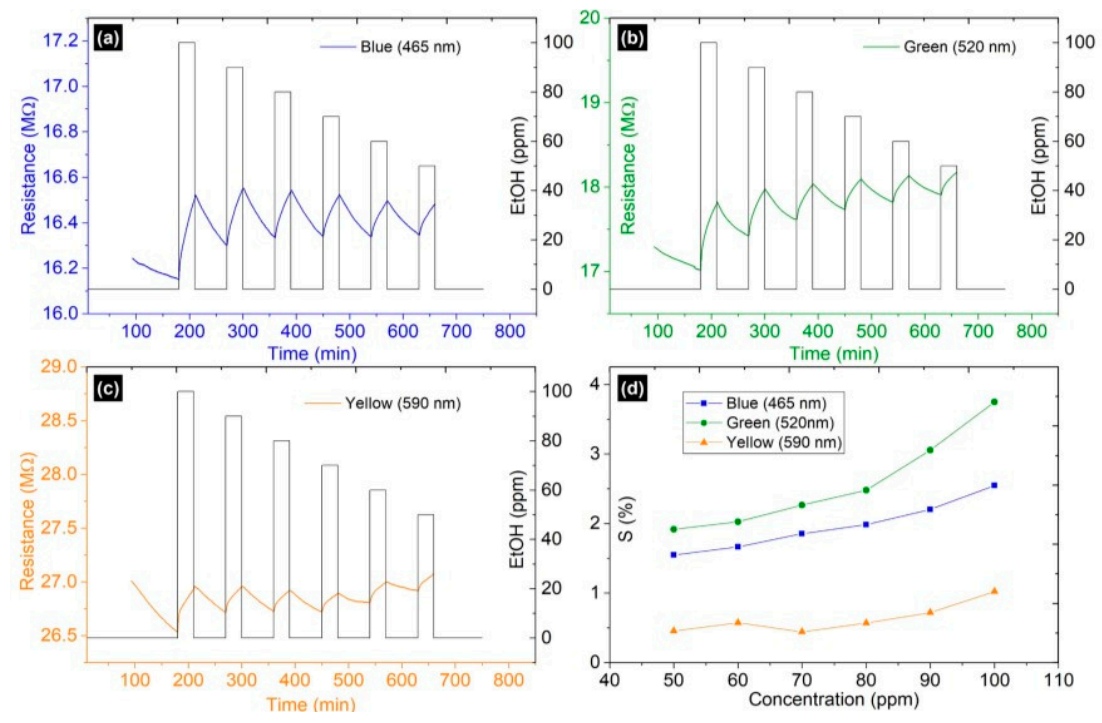

Figure 2. $\mathrm{CaFe}_{2} \mathrm{O}_{4}$ sensor responses in varied ethanol vapor concentrations (i.e., 50-100 ppm) under activation of (a) blue $(465 \mathrm{~nm})$, (b) green $(520 \mathrm{~nm})$, and (c) yellow $(590 \mathrm{~nm})$ LEDs. (d) Comparison of the sensor sensitivity under different light exposures.

\section{Conclusions}

Visible light activated at room temperature gas sensors based on metal oxide have been tested and validated. The maximum responses toward ethanol gas, response and recovery times were $3.7 \%$ 
at $100 \mathrm{ppm}, \sim 22 \mathrm{~min}$, and $\sim 49 \mathrm{~min}$, respectively. The results indicate that $\mathrm{CaFe}_{2} \mathrm{O}_{4}$ nanopowders synthesized by sol-gel auto-combustion method had good stability with visible light activation capability at room temperature, which can then be a promising candidate for the next generation of narrow bandgap MOX-based gas sensors.

Acknowledgments: The research leading to these results has received funding from the European Research Council under the European Union's Seventh Framework Programme (FP/2007-2013)/ERC Grant Agreement n. 336917. J.D. Prades acknowledges support from the Serra Húnter Programme. Qomaruddin thanks the Ministry of Research, Technology and Higher Education of the Republic of Indonesia (RISTEKDIKTI) for the PhD scholarship of RISET-Pro under ref. no. 348/RISET-Pro/FGS/VIII/2016 and Indonesian-German Center for Nano and Quantum Technologies (IG-Nano) for the support. H.S. Wasisto and A. Waag acknowledge the project funding support within LENA-OptoSense group from the Lower Saxony Ministry for Science and Culture (NMWK), Germany.

Conflicts of Interest: The author declares no conflict of interest.

\section{References}

1. Šutka, A.; Kodu, M.; Pärna, R.; Saar, R.; Juhnevica, I.; Jaaniso, R.; Kisand, V. Orthorhombic $\mathrm{CaFe}_{2} \mathrm{O}_{4}$ : A promising $p$-type gas sensor. Sens. Actuators B Chem. 2016, 224, 260-265, doi:10.1016/j.snb.2015.10.041.

2. Mirzaei, A.; Park, S.; Sun, G.-J.; Kheel, H.; Lee, C.; Lee, S. Fe2O3/Co3O4 composite nanoparticle ethanol sensor. J. Korean Phys. Soc. 2016, 69, 373-380, doi:10.3938/jkps.69.373.

3. Ivanovskaya, M.; Kotsikau, D.; Faflia, G.; Nelli, P.; Irkaev, S. Gas-sensitive properties of thin film heterojunction structures based on Fe2O3-In2O3 nanocomposites. Sens. Actuators B Chem. 2003, 93, $422-$ 430, doi:10.1016/S0925-4005(03)00175-8.

4. Geng, Q.; He, Z.; Chen, X.; Dai, W.; Wang, X. Gas sensing property of ZnO under visible light irradiation at room temperature. Sens. Actuators B Chem. 2013, 188, 293-297, doi:10.1016/j.snb.2013.07.001.

5. Prades, J.D.; Jimenez-Diaz, R.; Hernandez-Ramirez, F.; Barth, S.; Cirera, A.; Romano-Rodriguez, A.; Mathur, S.; Morante, J.R. Ultralow power consumption gas sensors based on self-heated individual nanowires. Appl. Phys. Lett. 2008, 93, 123110, doi:10.1063/1.2988265.

6. Fàbrega, C.; Casals, O.; Hernández-Ramírez, F.; Prades, J.D. A review on efficient self-heating in nanowire sensors: Prospects for very-low power devices. Sens. Actuators B Chem. 2018, 256, 797-811, doi:10.1016/j.snb.2017.10.003.

7. Prades, J.D.; Jimenez-Diaz, R.; Manzanares, M.; Hernandez-Ramirez, F.; Cirera, A.; Romano-Rodriguez, A.; Mathur, S.; Morante, J.R. A model for the response towards oxidizing gases of photoactivated sensors based on individual SnO2 nanowires. Phys. Chem. Chem. Phys. 2009, 11, 10881-10889, doi:10.1039/B915646A.

8. Prades, J.D.; Jiménez-Díaz, R.; Hernandez-Ramirez, F.; Barth, S.; Cirera, A.; Romano-Rodriguez, A.; Mathur, S.; Morante, J.R. Equivalence between thermal and room temperature UV light-modulated responses of gas sensors based on individual SnO2 nanowires. Sens. Actuators B Chem. 2009, 140, 337-341, doi:10.1016/j.snb.2009.04.070.

9. Gui, Y.; Li, S.; Xu, J.; Li, C. Study on TiO2-doped $\mathrm{ZnO}$ thick film gas sensors enhanced by UV light at room temperature. Microelectron. J. 2008, 39, 1120-1125, doi:10.1016/j.mejo.2008.01.052.

10. Liu, X.; Jiang, J.; Jia, Y.; Jin, A.; Chen, X.; Zhang, F.; Han, H. p-Type $\mathrm{CaFe}_{2} \mathrm{O}_{4}$ semiconductor nanorods controllably synthesized by molten salt method. J. Energy Chem. 2016, 25, 381-386, doi:10.1016/j.jechem.2016.03.019.

(C) 2018 by the authors. Licensee MDPI, Basel, Switzerland. This article is an open access article distributed under the terms and conditions of the Creative Commons Attribution (CC BY) license (http://creativecommons.org/licenses/by/4.0/). 